\title{
Technical Note: Simple formulations and solutions of the dual-phase diffusive transport for biogeochemical modeling
}

\author{
J. Y. Tang and W. J. Riley \\ Department of Climate and Carbon Sciences, Earth Sciences Division, Lawrence Berkeley National Lab (LBL), Berkeley, \\ CA, USA \\ Correspondence to: J. Y. Tang (jinyuntang@lbl.gov)
}

Received: 12 January 2014 - Published in Biogeosciences Discuss.: 23 January 2014

Revised: 10 June 2014 - Accepted: 12 June 2014 - Published: 17 July 2014

\begin{abstract}
Representation of gaseous diffusion in variably saturated near-surface soils is becoming more common in land biogeochemical models, yet the formulations and numerical solution algorithms applied vary widely. We present three different but equivalent formulations of the dual-phase (gaseous and aqueous) tracer diffusion transport problem that is relevant to a wide class of volatile tracers in land biogeochemical models. Of these three formulations (i.e., the gas-primary, aqueous-primary, and bulk-tracer-based formulations), we contend that the gas-primary formulation is the most convenient for modeling tracer dynamics in biogeochemical models. We then provide finite volume approximation to the gas-primary equation and evaluate its accuracy against three analytical models: one for steady-state soil $\mathrm{CO}_{2}$ dynamics, one for steady-state soil $\mathrm{CH}_{4}$ dynamics, and one for transient tracer diffusion from a constant point source into two different sequentially aligned medias. All evaluations demonstrated good accuracy of the numerical approximation. We expect our result will standardize an efficient mechanistic numerical method for solving relatively simple, multiphase, one-dimensional diffusion problems in land models.
\end{abstract}

\section{Introduction}

The interest in predicting fluxes of various biogenic greenhouse gases and their interactions with climate change has motivated the development of many terrestrial biogeochemical models; e.g., ecosystem methane models (Walter and Heiman, 2000; Zhuang et al., 2004; Tang et al., 2010; Riley et al., 2011), nitrification-denitrification models (Venterea and Rolston, 2000; Maggi et al., 2008), water- $\mathrm{CO}_{2}$ isotope mod- els (Riley et al., 2002), and generic reactive transport models that attempt to integrate as many biogeochemical processes and chemical species as possible (e.g., Simunek and Suarez, 1993; Grant, 2001; Tang et al., 2013). To resolve the depthdependent dynamics, these models in general represent multiphase (aqueous and gaseous phase) diffusion processes and often assume negligible advection.

The equation for multiphase diffusion has been represented in different forms by different authors (Table 1). However, the numerical implementation of the equation is often vaguely described (either by referring to other publications or by mentioning the numerical scheme) or is convolved with other technical details, making the model difficult to understand or replicate by other researchers. In many cases, however, one does not need to represent all the processes typically included in a complicated reactive transport model to understand a particular problem. For instance, when soil moisture and temperature data are available together with soil respiration, one only needs a diffusion model to evaluate belowground $\mathrm{CO}_{2}$ dynamics (Davidson et al., 2006). Therefore, ecosystem models would benefit from a simple mechanistic formulation and numerical implementation of the dualphase diffusion problem.

In this note, we categorize the existing formulations of the dual-phase diffusion problem into three forms, and recommend one that can be most easily implemented numerically in land models. We hope that this effort will help researchers who wish to develop simple but mechanistic transport models for their particular problem. 
Table 1. An incomplete literature survey of different formulations that have been used for modeling dual-phase diffusive transport.

\begin{tabular}{|c|c|c|}
\hline Equation & Remark & References \\
\hline$\frac{\partial C_{\mathrm{CH}_{4}}}{\partial t}=\frac{\partial}{\partial z}\left(D_{i} \frac{\partial C_{\mathrm{CH}_{4}}}{\partial z}\right)+S$ & $\begin{array}{l}\text { Bulk soil } \mathrm{CH}_{4} \text { concentration is the primary variable. Saturated and } \\
\text { unsaturated soil use different but constant diffusivities } D_{i} \text {. }\end{array}$ & $\begin{array}{l}\text { Walter and Heimann (2000), } \\
\text { Zhuang et al. (2004). }\end{array}$ \\
\hline$\frac{\partial R_{\mathrm{g}} C_{\mathrm{g}}}{\partial t}=\frac{\partial}{\partial z}\left(D \frac{\partial C_{\mathrm{g}}}{\partial z}\right)+S$ & $\begin{array}{l}\text { The gaseous phase is used as the primary variable. The model } \\
\text { assumes gas diffusion to dominate in unsaturated soil and aqueous } \\
\text { diffusion to dominate in saturated soil. The water table is assumed to } \\
\text { be at the layer interface. Diffusivity varies continuously with soil } \\
\text { moisture. }\end{array}$ & $\begin{array}{l}\text { Venterea and Rolston (2000), } \\
\text { Riley et al. (2011) }\end{array}$ \\
\hline$\frac{\partial C}{\partial t}=\frac{\partial}{\partial z}\left(D \frac{\partial C}{\partial z}\right)+S$ & $\begin{array}{l}\text { Bulk tracer concentration is used as the primary variable. Diffusivity } \\
\text { varies continuously with soil moisture. Special care is put to the } \\
\text { water-air interface. }\end{array}$ & Tang et al. (2010, 2013). \\
\hline $\begin{array}{l}\frac{\partial C_{\mathrm{g}}}{\partial t}=\frac{\partial}{\partial z}\left(D_{\mathrm{g}} \frac{\partial C_{\mathrm{g}}}{\partial z}\right)+S_{\mathrm{g}} \\
\frac{\partial C_{\mathrm{W}}}{\partial t}=\frac{\partial}{\partial z}\left(D_{\mathrm{W}} \frac{\partial C_{\mathrm{W}}}{\partial z}\right)+S_{\mathrm{W}}\end{array}$ & $\begin{array}{l}\text { Tracks gaseous and aqueous phases of a given tracer separately. Gas } \\
\text { dissolution and exsolution are considered explicitly. Diffusivity } \\
\text { varies continuously with moisture. }\end{array}$ & Maggi et al. (2008) \\
\hline
\end{tabular}

\section{Methods}

\subsection{Governing equations}

In this section we derive the relevant mass balance differential equations from first principles. Throughout this note we assume advection is treated using the operator splitting method (Tang et al., 2013), or is negligible. Considering the diffusive mass transport problem (Fig. 1), the dual-phase diffusive flux from layer $j-1$ into $j$ is

$$
\begin{aligned}
& F_{j-1 \rightarrow j}=F_{\mathrm{w}, j-1 \rightarrow j}+F_{\mathrm{g}, j-1 \rightarrow j} \\
& F_{\mathrm{w}, j-1 \rightarrow j}=-\left(\theta D_{\mathrm{w}} \frac{\partial C_{\mathrm{w}}}{\partial z}\right)_{j-\frac{1}{2}} \\
& F_{\mathrm{g}, j-1 \rightarrow j}=-\left(\varepsilon D_{\mathrm{g}} \frac{\partial C_{\mathrm{g}}}{\partial z}\right)_{j-\frac{1}{2}},
\end{aligned}
$$

where subscript $w$ indicates aqueous diffusion and subscript $\mathrm{g}$ indicates gaseous diffusion. Soil moisture is represented by $\theta$ and air-filled porosity by $\varepsilon$. The fluxes $\left(F_{j-1 \rightarrow j}\right)$ are imposed at the upper and lower boundaries of layer $j$. Tracer concentrations are designated by $C$ with appropriate subscripts. In defining the effective aqueous $\left(D_{\mathrm{w}}\right)$ and gaseous $\left(D_{\mathrm{g}}\right)$ diffusivities, we assume the tortuosity has been considered appropriately (e.g., Moldrup et al., 2003). A full list of symbols is given in Appendix Table A1.

Applying the law of mass balance to layer $j$

$$
\begin{aligned}
\Delta z_{j} \frac{\Delta C_{j}}{\Delta t} & =F_{j-1 \rightarrow j}-F_{j \rightarrow j+1}=\left(F_{\mathrm{w}, j-1 \rightarrow j}-F_{\mathrm{w}, j \rightarrow j+1}\right) \\
& +\left(F_{\mathrm{g}, j-1 \rightarrow j}-F_{\mathrm{g}, j \rightarrow j+1}\right)+S_{j} \Delta z_{j}
\end{aligned}
$$

and in the limit of small $\Delta z_{j}$ and $\Delta t$, one obtains

$$
\frac{\partial C}{\partial t}=\frac{\partial}{\partial z}\left(\theta D_{\mathrm{w}} \frac{\partial C_{\mathrm{w}}}{\partial z}\right)+\frac{\partial}{\partial z}\left(\varepsilon D_{\mathrm{g}} \frac{\partial C_{\mathrm{g}}}{\partial z}\right)+S(C, z)
$$

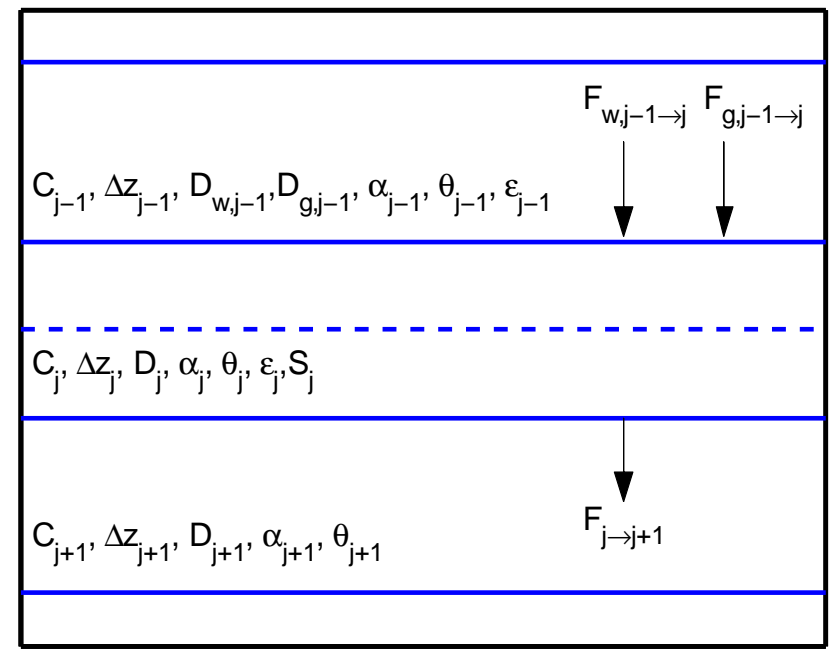

Figure 1. Schematic of the dual-phase diffusive transport problem: solid lines are the interfaces between control volumes and the dashed line is the center of the control volume. All symbols are defined in Appendix Table A1.

where $S(C, z)$ is the tracer source due to processes other than diffusion and $C$ is the bulk tracer concentration including both gaseous and aqueous phases. From the assumption of equilibrium between aqueous and gaseous phases (e.g., Tang et al., 2010):

$$
\begin{aligned}
C & =\theta C_{\mathrm{w}}+\varepsilon C_{\mathrm{g}}=R_{\mathrm{g}} C_{\mathrm{g}}=(\theta \alpha+\varepsilon) C_{\mathrm{g}} \\
& =R_{\mathrm{w}} C_{\mathrm{w}}=\left(\theta+\frac{\varepsilon}{\alpha}\right) C_{\mathrm{w}},
\end{aligned}
$$

where $\alpha$ is the Bunsen solubility coefficient, one obtains, from substitution of Eq. (3) into the diffusion and temporal 
derivative of Eq. (2b):

$R_{\mathrm{g}} \frac{\partial C_{\mathrm{g}}}{\partial t}=\frac{\partial}{\partial z}\left[\left(\alpha \theta D_{\mathrm{w}}+\varepsilon D_{\mathrm{g}}\right) \frac{\partial C_{\mathrm{g}}}{\partial z}\right]+S(C, z)$

$R_{\mathrm{W}} \frac{\partial C_{\mathrm{w}}}{\partial t}=\frac{\partial}{\partial z}\left[\left(\theta D_{\mathrm{w}}+\frac{\varepsilon}{\alpha} D_{\mathrm{g}}\right) \frac{\partial C_{\mathrm{w}}}{\partial z}\right]+S(C, z)$.

By further defining a bulk diffusivity

$D=\frac{\alpha \theta D_{\mathrm{w}}+\varepsilon D_{\mathrm{g}}}{R_{\mathrm{g}}}=\frac{\theta D_{\mathrm{w}}+\varepsilon D_{\mathrm{g}} / \alpha}{R_{\mathrm{w}}}$

and assuming

$\left|\frac{1}{C_{x}} \frac{\partial C_{x}}{\partial t}\right| \gg\left|\frac{1}{R_{x}} \frac{\partial R_{x}}{\partial t}\right|,\left|\frac{1}{C_{x}} \frac{\partial C_{x}}{\partial z}\right| \gg\left|\frac{1}{R_{x}} \frac{\partial R_{x}}{\partial z}\right|, x=$ w or $\mathrm{g}$

one finds for the bulk tracer:

$\frac{\partial C}{\partial t}=\frac{\partial}{\partial z}\left(D \frac{\partial C}{\partial z}\right)+S(C, z)$.

Clearly, Eq. (4a) (gas-primary form), Eq. (4b) (aqueousprimary form), and Eq. (7) (bulk tracer form) are equivalent, but Eq. (4) are more convenient to solve because the tracer sources are in general given as aqueous reactions or gaseous sinks (e.g., plant transport, ebullition) and the necessary phase conversion can be done easily through Eq. (3). In particular, Eq. (4a) (the gas-primary form) is the most convenient for simulating volatile tracers and can be applied to variably saturated soil without the need for special care of the air-water interface, as was done in a few existing wetland$\mathrm{CH}_{4}$ models (see remark in Table 1). We note that Eq. (4a) was also used by Simunek and Suarez (1993) to model $\mathrm{CO}_{2}$ transport in soil.

At the top boundary, conditions are in general given as gas tracer concentrations, which are connected to the gas concentration of the top numerical layer as

$F_{\mathrm{g}, 0 \rightarrow 1}=-\frac{C_{\mathrm{g}, 1}-C_{\mathrm{a}}}{r_{\mathrm{a}}+r_{\mathrm{s}}}$,

where $r_{\mathrm{a}}$ is atmospheric resistance and $r_{\mathrm{s}}$ is soil resistance (see Tang and Riley, 2013 for a detailed discussion).

At the bottom boundary, zero flux conditions are often imposed, though zero concentration can also be used for particular problems. In practice, if a tracer exists only in the aqueous phase, then one can solve Eq. (4b) for aqueous diffusive transport by setting $\alpha \rightarrow \infty$ and using a zero-flux boundary condition at the top and bottom boundaries.

\subsection{Numerical implementation}

We now solve Eq. (4a) using the finite volume method. First, we discretize the equation spatially and convert it into the following ordinary differential equation (ODE) system,

$\operatorname{diag}\left(\boldsymbol{Z}_{\mathrm{g}}\right) \frac{\mathrm{d} \boldsymbol{C}_{\mathrm{g}}}{\mathrm{d} t}=\mathbf{A} \boldsymbol{C}_{\mathrm{g}}+\boldsymbol{S}$, where $\operatorname{diag}(\boldsymbol{V})$ indicates a diagonal matrix formed by the vector $\boldsymbol{V}$ and

$\boldsymbol{C}=\left[\begin{array}{lllll}C_{\mathrm{g}, 1} & \cdots & C_{\mathrm{g}, j} & \cdots & C_{\mathrm{g}, N}\end{array}\right]^{T}$

$\mathbf{A}=\left[\begin{array}{ccccc}-c_{1 / 2}-c_{3 / 2} & c_{3 / 2} & 0 & \cdots & 0 \\ \vdots & \vdots & \vdots & \ldots & 0 \\ \cdots & c_{j-1 / 2} & -c_{j-1 / 2}-c_{j+1 / 2} & c_{j+1 / 2} & \cdots \\ \vdots & 0 & \ldots & \ldots & \vdots \\ 0 & \cdots & 0 & c_{N-1 / 2} & -c_{N-1 / 2}-c_{N+1 / 2}\end{array}\right]$

$$
\begin{aligned}
\boldsymbol{S}= & {\left[S\left(C_{1}, z_{1}\right) \Delta z_{1}+c_{1 / 2} C_{\mathrm{a}} \ldots S\left(C_{j}, z_{j}\right) \Delta z_{j}\right.} \\
& \left.\ldots S\left(C_{N}, z_{N}\right) \Delta z_{N}+c_{N+1 / 2} C_{\mathrm{b}}\right]^{T} \\
\boldsymbol{Z}_{\mathrm{g}}= & {\left[R_{\mathrm{g}, 1} \Delta z_{1} \ldots R_{\mathrm{g}, j} \Delta z_{j} \ldots R_{\mathrm{g}, N} \Delta z_{N}\right] }
\end{aligned}
$$

Other coefficients are defined as

$D_{\mathrm{wg}, j}=\alpha_{j} \theta_{j} D_{\mathrm{w}, j}+\varepsilon_{j} D_{\mathrm{g}, j}, \quad 1<j \leq N$

$c_{j-1 / 2}=\left(\frac{\Delta z_{j-1}}{2 D_{\mathrm{wg}, j-1}}+\frac{\Delta z_{j}}{2 D_{\mathrm{wg}, j}}\right)^{-1}, \quad 1<j \leq N$

$c_{1 / 2}=\frac{1}{r_{\mathrm{a}}+r_{\mathrm{s}}}$.

Conductance $c_{N+1 / 2}$ is zero when zero flux bottom boundary condition is used, but here it is included to enable Eq. (9) to accommodate the bottom boundary condition given as a constant tracer concentration $\left(C_{\mathrm{b}}\right)$. For this latter case, one can simply set $c_{N+1 / 2}$ to $c_{N-1 / 2}$.

The ODE system formed by Eq. (9) (together with Eq. 10) can be easily solved with various temporal discretization methods. For instance, the ODE solvers (e.g., ODE45, ODE23) in MATLAB provide a very straightforward way to obtain the solutions. In addition, we point out that by solving the equation implicitly with a very large time step (as we have done for our evaluation against steady-state analytical results below), Eq. (9) can also provide the steady state solution that has been used in several models to derive rates of soil methane consumption and production (Curry, 2007; Zhuang et al., 2004, 2013). However, our formulation is more general and can be applied to model multiple gas species simultaneously.

The aqueous-primary equation Eq. (4b) can be solved analogously, but it should be processed with appropriate definitions of the conductances.

\subsection{Evaluation with analytic models}

We used two steady-state analytic models and one transient analytical model to evaluate the spatial discretization in Eqs. (9) and (10).

The first analytical model is the steady-state $\mathrm{CO}_{2}$ diffusion model presented in Tans (1998), but we added aqueous diffusion, which was not included in his Eq. (2). The governing 
equation of the modified Tans model is

$$
\left(\varepsilon D_{\mathrm{g}}+\theta D_{\mathrm{w}}\right) \frac{\mathrm{d}^{2} C_{\mathrm{g}}}{\mathrm{d} z^{2}}+S_{o} \exp \left(-\frac{z}{z_{0}}\right)=0,
$$

whose solution is

$C_{\mathrm{g}}(z)=\frac{S_{o}}{\varepsilon D_{\mathrm{g}}+\theta D_{\mathrm{w}}} z_{0}^{2}\left[1-\exp \left(-\frac{z}{z_{0}}\right)\right]+C_{\mathrm{a}}$.

We list the parameter values used in our example application in Table 2.

We craft the second model to mimic the methane cycle in a peatland, with methane consumption in the unsaturated topsoil (defined as from the soil surface to depth $z_{1}$, below which the soil is saturated) and a constant methane production from depth $z_{1}$ to $z_{2}$. We could have replicated published methane models and compared with porewater $\mathrm{CH}_{4}$ concentrations, but other uncertainties (e.g., uncertainties in parameterization, formulation, and measurement) would obfuscate a direct evaluation of the accuracy of our diffusive transport numerical formulation.

The governing equation of the steady-state methane model is

$$
\begin{aligned}
& \left(\varepsilon_{1} D_{\mathrm{g}}+\alpha \theta_{1} D_{\mathrm{w}}\right) \frac{\mathrm{d}^{2} C_{\mathrm{g}}}{\mathrm{d} z^{2}}-Q_{1} \theta_{1} C_{\mathrm{w}}=0, \text { for } 0 \leq z \leq z_{1} \\
& \left(\alpha \theta_{2} D_{\mathrm{w}}\right) \frac{\mathrm{d}^{2} C_{\mathrm{g}}}{\partial z^{2}}+Q_{2}=0, \text { for } z_{1}<z<z_{2} \\
& {\left[\left(\varepsilon_{1} D_{\mathrm{g}}+\alpha \theta_{1} D_{\mathrm{w}}\right) \frac{\mathrm{d} C_{\mathrm{g}}}{\mathrm{d} z}\right]_{z_{1}^{-}}=\left(\alpha \theta_{s} D_{\mathrm{w}} \frac{\mathrm{d} C_{\mathrm{g}}}{\mathrm{d} z}\right)_{z_{1}^{+}}} \\
& \frac{\mathrm{d} C_{\mathrm{g}}}{\mathrm{d} z}=0, \text { for } z \geq z_{2},
\end{aligned}
$$

whose solution is found (see Supplement) as

$$
\begin{gathered}
\begin{array}{c}
C_{\mathrm{g}}(z)=\frac{C_{\mathrm{a}} \exp \left(\sqrt{\frac{\alpha \theta_{1} Q_{1}}{D_{1}}} z_{1}\right)-\frac{Q_{2}}{D_{1}} \sqrt{\frac{D_{1}}{\alpha \theta_{1} Q_{1}}}\left(z_{2}-z_{1}\right)}{\exp \left(-\sqrt{\frac{\alpha \theta_{1} Q_{1}}{D_{1}}} z_{1}\right)+\exp \left(\sqrt{\frac{\alpha \theta_{1} Q_{1}}{D_{1}}} z_{1}\right)} \exp \left(-\sqrt{\frac{\alpha \theta_{1} Q_{1}}{D_{1}}} z\right) \\
+\frac{C_{\mathrm{a}} \exp \left(-\sqrt{\frac{\alpha \theta_{1} Q_{1}}{D_{1}}} z_{1}\right)+\frac{Q_{2}}{D_{1}} \sqrt{\frac{D_{1}}{\alpha \theta_{1} Q_{1}}}\left(z_{2}-z_{1}\right)}{\exp \left(-\sqrt{\frac{\alpha \theta_{1} Q_{1}}{D_{1}}} z_{1}\right)+\exp \left(\sqrt{\frac{\alpha \theta_{1} Q_{1}}{D_{1}}} z_{1}\right)} \exp \left(\sqrt{\frac{\alpha \theta_{1} Q_{1}}{D_{1}}} z\right), \\
\text { for } 0 \leq z \leq z_{1} \\
C_{\mathrm{g}}(z)=\frac{Q_{2}}{D_{2}}\left(z-z_{1}\right)\left(z_{2}-z_{1}\right)-\frac{Q_{2}}{2 D_{2}}\left(z-z_{1}\right)^{2} \\
+C_{\mathrm{g}}\left(z_{1}\right), \text { for } z_{1}<z<z_{2} \\
C_{\mathrm{g}}(z)=\frac{Q_{2}}{2 D_{2}}\left(z_{2}-z_{1}\right)^{2}+C_{\mathrm{g}}\left(z_{1}\right), \text { for } z \geq z_{2},
\end{array}
\end{gathered}
$$

where $D_{1}=\varepsilon_{1} D_{\mathrm{g}}+\alpha \theta_{1} D_{\mathrm{w}}$ and $D_{2}=\alpha \theta_{2} D_{\mathrm{w}}$. Parameter values used in our example application are listed in Table 3.

The transient model considers the release of a tracer from a constant point source $\left(C_{0}\right)$ into a media, which is connected
Table 2. Parameters used for the steady-state $\mathrm{CO}_{2}$ model.

\begin{tabular}{ll}
\hline Parameter & Value and units \\
\hline$C_{\mathrm{a}}$ & $0.0143 \mathrm{~mol} \mathrm{~m}^{-3}$ \\
$D_{\mathrm{g}}$ & $9.33 \times 10^{-6} \mathrm{~m}^{2} \mathrm{~s}^{-1}$ \\
$D_{\mathrm{W}}$ & $6.667 \times 10^{-10} \mathrm{~m}^{2} \mathrm{~s}^{-1}$ \\
$f_{\mathrm{s}, 1}$ & $0.025 \mathrm{~m}$ \\
$f_{\mathrm{s}, 2}$ & 0.25 for $N=20,0.05$ for $N=100$ \\
$S_{0}$ & $1 \mathrm{~mol} \mathrm{day}$ \\
$z_{0}$ & $0.4 \mathrm{~m}$ \\
$\alpha$ & 0.76 \\
$\varepsilon$ & $0.2 \mathrm{~m}^{3} \mathrm{~m}^{-3}$ \\
$\theta$ & $0.3 \mathrm{~m}^{3} \mathrm{~m}^{-3}$ \\
\hline
\end{tabular}

Table 3. Parameters used for the steady-state $\mathrm{CH}_{4}$ model.

\begin{tabular}{ll}
\hline Parameter & Value and units \\
\hline$C_{\mathrm{a}}$ & $6.939 \times 10^{-5} \mathrm{~mol} \mathrm{~m}^{-3}$ \\
$D_{\mathrm{g}}$ & $1.267 \times 10^{-5} \mathrm{~m}^{2} \mathrm{~s}^{-1}$ \\
$D_{\mathrm{w}}$ & $1.33 \times 10^{-10} \mathrm{~m}^{2} \mathrm{~s}^{-1}$ \\
$f_{\mathrm{s}, 1}$ & $0.025 \mathrm{~m}$ \\
$f_{\mathrm{s}, 2}$ & 0.25 for $N=20,0.05$ for $N=100$ \\
$Q_{1}$ & $10^{-6} \mathrm{~s}^{-1}$ \\
$Q_{2}$ & $10^{-11} \mathrm{~mol} \mathrm{~s}^{-1}$ \\
$z_{1}$ & $0.1 \mathrm{~m}$ \\
$z_{2}$ & $0.4 \mathrm{~m}$ \\
$\alpha$ & 0.0318 \\
$\varepsilon_{1}$ & $0.2 \mathrm{~m}^{3} \mathrm{~m}^{-3}$ \\
$\theta_{1}$ & $0.3 \mathrm{~m}^{3} \mathrm{~m}^{-3}$ \\
$\theta_{2}$ & $0.5 \mathrm{~m}^{3} \mathrm{~m}^{-3}$ \\
\hline
\end{tabular}

to another media at some distance $z_{1}$. The tracer has different diffusivities and solubilities in the two media, and its concentration is kept zero at the bottom of the second media. The model solves for the temporal evolution of the tracer in both media. Mathematically, the model is formulated as

$$
\begin{aligned}
& \frac{\partial C_{\mathrm{g}}}{\partial t}=D_{\mathrm{g}} \frac{\partial^{2} C_{\mathrm{g}}}{\partial z^{2}}, \text { for } 0<z<z_{1} \\
& \frac{\partial C_{\mathrm{g}}}{\partial t}=D_{\mathrm{w}} \frac{\partial^{2} C_{\mathrm{g}}}{\partial z^{2}}, \text { for } z_{1}<z<L \\
& \left(D_{\mathrm{g}} \frac{\partial C_{\mathrm{g}}}{\partial z}\right)_{z_{1}^{-}}=\left(D_{\mathrm{w}} \alpha \frac{\partial C_{\mathrm{g}}}{\partial z}\right)_{z_{1}^{+}} \\
& C_{\mathrm{g}}\left(z_{1}^{+}\right)=C_{\mathrm{g}}\left(z_{1}^{-}\right),
\end{aligned}
$$

where we note the variables in Eq. (15) are now not necessarily related to gaseous and aqueous phases, but we simply keep the denotations for simplicity. The initial condition to Eq. (15) is set as zero tracer concentration everywhere inside the column.

The model represented by Eq. (15) can represent a few different problems, such as contaminant diffusion from human skin into blood (e.g., Riley et al., 2004) or heat conduction 
between two metals of an alloy (e.g., Carslaw and Jaeger, 1986). When all coefficients are given as constant, Eq. (15) has the analytic solution (Carslaw and Jaeger, 1986):

$C_{\mathrm{g}}\left(z \leq z_{1}\right)=\frac{C_{0}\left(D_{\mathrm{g}} L / \alpha-D_{\mathrm{w}} s\right)}{D_{\mathrm{g}} L / \alpha+D_{\mathrm{w}} z_{1}}$

$-2 C_{0} \sum_{n=1}^{\infty} \frac{\sin ^{2}\left(k L \beta_{n}\right) \sin \left(\beta_{n} z\right)}{\beta_{n}\left[z_{1} \sin ^{2}\left(k L \beta_{n}\right)+\alpha L \sin ^{2}\left(z_{1} \beta_{n}\right)\right]} \exp \left(-D_{\mathrm{g}} \beta_{n}^{2} t\right)$

$C_{\mathrm{g}}\left(z \geq z_{1}\right)=\frac{D_{\mathrm{g}} C_{0}(L-s)}{D_{\mathrm{g}} L+D_{\mathrm{w}} z_{1} \alpha}$

$-2 C_{0} \sum_{n=1}^{\infty} \frac{\sin \left(z_{1} \beta_{n}\right) \sin \left(k L \beta_{n}\right) \sin \left(k(L-s) \beta_{n}\right)}{\beta_{n}\left[z_{1} \sin ^{2}\left(k L \beta_{n}\right)+\alpha L \sin ^{2}\left(z_{1} \beta_{n}\right)\right]} \exp \left(-D_{\mathrm{g}} \beta_{n}^{2} t\right)$

where $s=z-z_{1}, k=\sqrt{D_{\mathrm{g}} / D_{\mathrm{w}}}$. The eigenvalues, $\beta_{n}$, are solutions of

$\cos \left(\beta z_{1}\right) \sin (k \beta L)+\sigma \sin \left(\beta z_{1}\right) \cos (k \beta L)=0$,

which is solved by Newton iteration methods. In evaluating Eq. (16), we only used the first 17 eigenvalues, because more eigenvalues did not significantly improve the estimation. Parameter values for the example application are listed in Table 4 .

In all numerical experiments, we discretized the vertical soil profile using a scheme modified from CLM4.5 (Oleson et al., 2013), which defines the node depth of layer $j$ as

$z_{j}=\left\{\begin{array}{l}f_{\mathrm{s}, 1}\left\{\exp \left[f_{\mathrm{s}, 2}(j-0.5)\right]-1\right\}, j=1, \ldots, N-1 \\ \left(2 L+z_{N-1}\right) / 3 \quad j=N\end{array}\right.$

and the thickness of each layer as

$\Delta z_{j}=\left\{\begin{array}{l}0.5\left(z_{1}+z_{2}\right) \quad j=1 \\ 0.5\left(z_{j+1}-z_{j-1}\right) \quad j=2,3, \cdots, N-1 \\ 2\left(L-z_{N-1}\right) / 3 \quad j=N\end{array}\right.$

and the depth at interfaces as

$z_{h, j}=\left\{\begin{array}{l}0.5\left(z_{j}+z_{j+1}\right) \quad j=1,2, \cdots, N-1 \\ z_{N}+0.5 \Delta z_{N} \quad j=N\end{array}\right.$

For all numerical experiments, the total soil column depth is set to $3.7 \mathrm{~m}$. For the numerical approximation to the transient problem, the Crank-Nicholson method (Crank and Nicholson, 1947) is used for temporal discretization.

\section{Results and discussion}

Driven by the prescribed $\mathrm{CO}_{2}$ source (Fig. 2a), the numerical solution using 100 numerical layers predicts a soil $\mathrm{CO}_{2}$ profile very close to the exact solution throughout the soil column (Fig. 2b). The maximum relative error is about $0.2 \%$, which is hard to discern visually. Decreasing the number of numerical layers to 20 leads to visually discernible deviations
Table 4. Parameters used for the transient tracer diffusion model.

\begin{tabular}{ll}
\hline Parameter & Values and units \\
\hline$C_{0}$ & $1 \mathrm{~mol} \mathrm{~m}^{-3}$ \\
$D_{\mathrm{g}}$ & $5 \times 10^{-6} \mathrm{~m}^{2} \mathrm{~s}^{-1}$ \\
$D_{\mathrm{w}}$ & $5 \times 10^{-4} \mathrm{~m}^{2} \mathrm{~s}^{-1}$ \\
$f_{\mathrm{s}, 1}$ & $0.025 \mathrm{~m}$ \\
$f_{\mathrm{s}, 2}$ & 0.25 for $N=20,0.05$ for $N=100$ \\
$z_{1}$ & $0.15 \mathrm{~m}$ \\
$\alpha$ & 0.1 \\
\hline
\end{tabular}
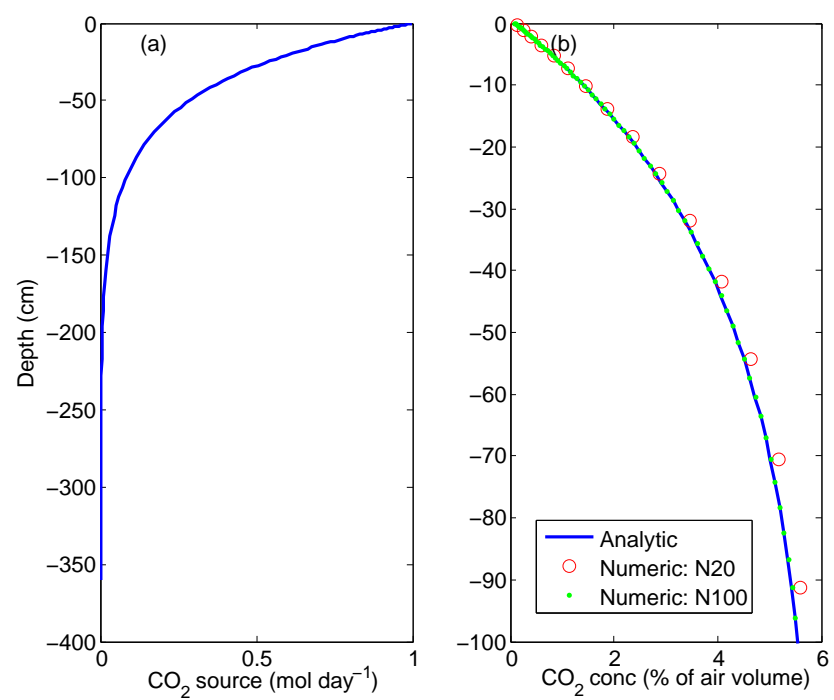

Figure 2. Comparison between the numerical and analytical solutions for the steady-state soil $\mathrm{CO}_{2}$ model: (a) net $\mathrm{CO}_{2}$ source profile, as specified in the second term of Eq. (11); (b) analytical and predicted soil $\mathrm{CO}_{2}$ profiles. N20 indicates solution using 20 numerical layers and N100 indicates solution using 100 numerical layers. At the top boundary, the $\mathrm{CO}_{2}$ concentration equals $350 \mathrm{ppmv}$.

from the analytic solution and the maximum relative error increases to $\sim 4 \%$. However, the maximum relative error in both cases is near the surface, where the $\mathrm{CO}_{2}$ concentration is low. The 20- and 100-layer simulations predict a surface $\mathrm{CO}_{2}$ efflux of about 1 and $0.03 \%$ accuracy, respectively, with respect to the analytical flux. These results indicate our numerical technique is sufficient for most soil dual-phase diffusion modeling applications.

The evaluation of the $\mathrm{CH}_{4}$ numerical solution against the analytical $\mathrm{CH}_{4}$ model in general shows good accuracy. As for $\mathrm{CO}_{2}$, more numerical layers lead to better numerical accuracy. Both 20-layer and 100-layer solutions indicate significant deviations from the analytical soil $\mathrm{CH}_{4}$ profile, but the largest relative error is about $5 \%$ for the 20-layer simulation and less than $1 \%$ for the 100-layer simulation. The largest relative error occurs at the bottom of the topsoil $(10 \mathrm{~cm})$ in both cases. Because of the numerical approximation, both numerical solutions do not have numerical 

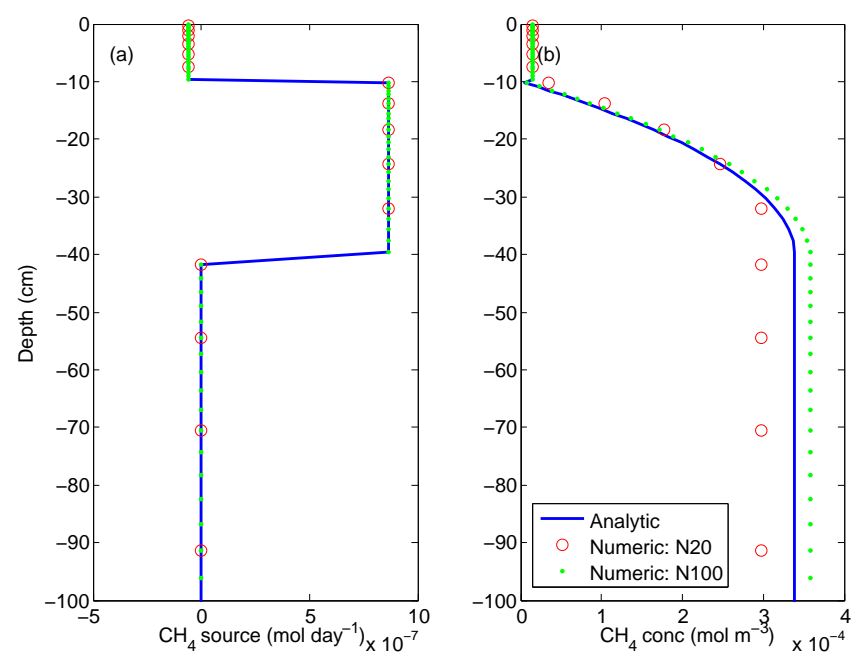

Figure 3. Comparison between the numerical and analytical solutions for the steady-state soil methane model: (a) net $\mathrm{CH}_{4}$ source profiles and (b) soil gaseous $\mathrm{CH}_{4}$ profiles. N20 indicates the solution using 20 numerical layers and N100 indicates the solution using 100 numerical layers.

layers interfaced at $10 \mathrm{~cm}$, which, when combined with the abrupt transition from the first-order consumption in topsoil to the constant methane production rate between $10 \mathrm{~cm}$ and $40 \mathrm{~cm}$, lead to the largest relative error. Nevertheless, considering that the 20-layer and 100-layer solutions have 7 and $3 \%$ relative error, respectively, in approximating the surface methane fluxes, the numerical algorithm should again satisfy the needs of modeling methane dynamics in ecosystem biogeochemical models.

For the transient model, we first compared the temporal evolution of tracer concentrations at three depths $(7,15$, and $200 \mathrm{~cm}$ ) (Fig. 4a, b, and c, respectively). Again, both the 20layer and 100-layer simulations show visually very accurate results (with mean relative error less than $5 \%$ for the 20 layer and less than $1 \%$ for the 100-layer), though there are large errors $(>100 \%)$ in the first 10 minutes of the simulations (when tracer concentrations are very low), which are probably caused by errors in both the finite volume approximation and the numerical error in evaluating the analytic results (see Supplement Fig. S1 for the latter case). When the steady-state solutions are compared (Fig. 4d), the two numerical models show mean relative error within $2 \%$, indicating our numerical algorithms are very accurate. In both transient and steady-state cases, the numerically predicted top surface fluxes agree with the analytical solution with a mean relative error within $10 \%$ for the 20 -layer and $2 \%$ for the 100-layer simulations, respectively, after the first 20 minutes of simulation.
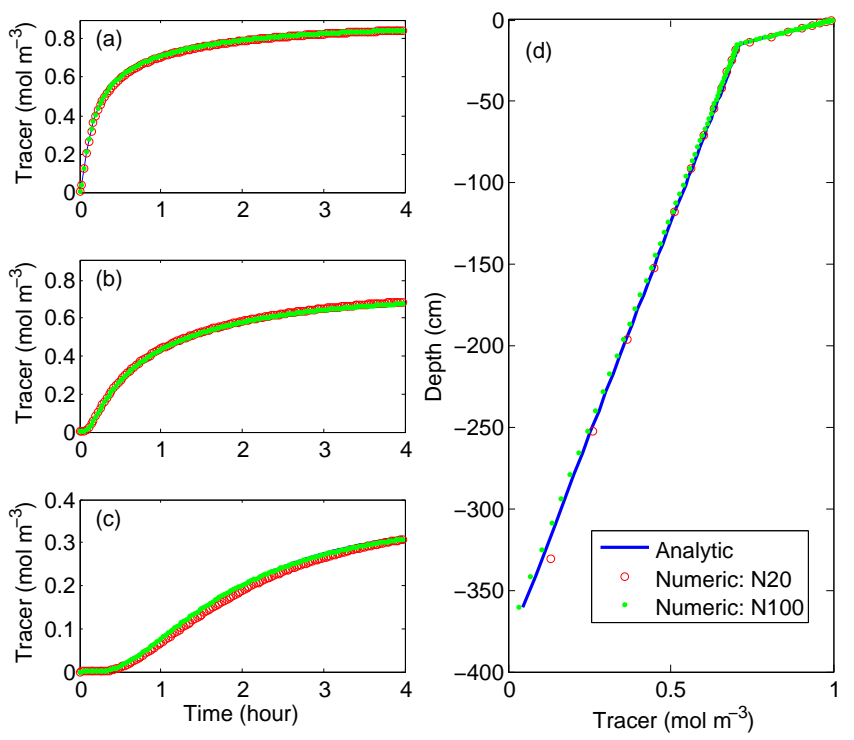

Figure 4. Comparison between the numerical and analytical solutions for the point source tracer diffusion model: (a) temporal evolution of tracer concentration at $7 \mathrm{~cm}$; (b) temporal evolution of tracer concentration at $15 \mathrm{~cm}$; (c) temporal evolution of tracer concentration at $200 \mathrm{~cm}$; and (d) steady-state solution. N20 indicates the solution using 20 numerical layers and N100 indicates the solution using 100 numerical layers.

To summarize from the three evaluations, we contend Eq. (4a) and its approximation Eq. (9) should be very helpful for solving the dual-phase diffusion problem.

\section{Conclusions}

Dual-phase diffusion is an important process that needs to be represented in depth-resolved biogeochemical models. Here we reviewed existing formulations in the literature and categorized three forms used in biogeochemical models. We recommend that the gas-primary form (Eq. $4 \mathrm{a}$ ) is the most convenient to solve. Its finite volume approximation can represent tracer transport in variably saturated soils without the need for special treatment of the air-water interface (as is often done in existing methane models). Our evaluation of the numerical algorithm with three analytical models demonstrated good accuracy of our numerical model, with some dependence on spatial discretization. We hope our results can help researchers develop simple but mechanistic models for some scientific questions where more complex reactivetransport models are not necessary. 


\section{Appendix A}

Table A1. Symbols used in paper, their definitions and corresponding units.

\begin{tabular}{|c|c|c|}
\hline Symbol & Definition & Units \\
\hline$C_{\mathrm{a}}$ & Atmospheric tracer concentration & $\mathrm{mol} \mathrm{m}^{-3}$ \\
\hline$C_{0}$ & Point tracer source concentration & $\mathrm{mol} \mathrm{m}^{-3}$ \\
\hline$C_{\mathrm{g}}, C_{\mathrm{w}}$ and $C$ & Gaseous, aqueous and bulk tracer concentration & $\mathrm{mol} \mathrm{m}^{-3}$ \\
\hline$c_{j-1 / 2}$ & Tracer conductance between layer $j$ and $j-1$ & $\mathrm{~ms}^{-1}$ \\
\hline$D_{\mathrm{g}}, D_{\mathrm{w}}$ and $D$ & Gaseous, aqueous and bulk diffusivity & $\mathrm{m}^{2} \mathrm{~s}^{-1}$ \\
\hline$D_{\mathrm{wg}, j}$ & Weighted tracer diffusivity in layer $j$ & $\mathrm{~m}^{2} \mathrm{~s}^{-1}$ \\
\hline$F_{\mathrm{w}, j-1 \rightarrow j}$ & Aqueous tracer flux from layer $j-1$ to layer $j$ & $\mathrm{~mol} \mathrm{~m}^{-2} \mathrm{~s}^{-1}$ \\
\hline$F_{\mathrm{a}, j-1 \rightarrow j}$ & Gaseous tracer flux from layer $j-1$ to layer $j$ & $\mathrm{~mol} \mathrm{~m}^{-2} \mathrm{~s}^{-1}$ \\
\hline$F_{j-1 \rightarrow j}$ & Bulk tracer flux from layer $j-1$ to layer $j$ & $\mathrm{~mol} \mathrm{~m}^{-2} \mathrm{~s}^{-1}$ \\
\hline$F_{\mathrm{g}, 0 \rightarrow 1}$ & Gaseous tracer fluxes from atmosphere into soil & $\mathrm{mol} \mathrm{m}^{-2} \mathrm{~s}^{-1}$ \\
\hline$f_{\mathrm{s}, 1}$ & Scaling parameter for numerical discretization & $\mathrm{m}$ \\
\hline$f_{\mathrm{s}, 2}$ & Scaling parameter for numerical discretization & None \\
\hline$j$ & Layer indices & None \\
\hline$L$ & Column depth & $\mathrm{m}$ \\
\hline$N$ & Total number of numerical layers & None \\
\hline$Q_{1}$ & $\mathrm{CH}_{4}$ consumption rate & $\mathrm{s}^{-1} \mathrm{~s}$ \\
\hline$Q_{2}$ & $\mathrm{CH}_{4}$ production rate & $\mathrm{mol} \mathrm{m}^{-3} \mathrm{~s}^{-1}$ \\
\hline$R_{\mathrm{g}}$ and $R_{\mathrm{W}}$ & $\begin{array}{l}\text { Parameters to convert gaseous and aqueous tracer } \\
\text { concentrations into accordant bulk concentrations }\end{array}$ & None \\
\hline$r_{\mathrm{a}}$ and $r_{\mathrm{s}}$ & Atmospheric resistance and soil resistance & $\mathrm{s} \mathrm{m}^{-1}$ \\
\hline$S_{j}, S\left(C_{\mathrm{w}}, z\right)$ & Net tracer source & $\mathrm{mol} \mathrm{m}^{-3} \mathrm{~s}^{-1}$ \\
\hline$S_{0}$ & Total $\mathrm{CO}_{2}$ production rate & $\mathrm{mol} \mathrm{m}^{-3} \mathrm{~s}^{-1}$ \\
\hline$z, z_{j}$ and $z_{h, j}$ & Numerical layer depths & $\mathrm{m}$ \\
\hline$z_{0}$ & e-folding depth for soil $\mathrm{CO}_{2}$ production & $\mathrm{m}$ \\
\hline$z_{1}$ & Beginning of the production zone for the $\mathrm{CH}_{4}$ model & $\mathrm{m}$ \\
\hline$z_{2}$ & Ending of the production zone for the $\mathrm{CH}_{4}$ model & $\mathrm{m}$ \\
\hline$\Delta z_{j}$ & Numerical node thickness & $\mathrm{m}$ \\
\hline$\alpha$ & Bunsen solubility coefficient & None \\
\hline$\theta$ & Soil moisture & $\mathrm{m}^{3} \mathrm{~m}^{-3}$ \\
\hline$\varepsilon$ & Air-filled soil porosity & $\mathrm{m}^{3} \mathrm{~m}^{-3}$ \\
\hline
\end{tabular}




\section{The Supplement related to this article is available online at doi:10.5194/bg-11-3721-2014-supplement.}

Acknowledgements. This research was supported by the Director, Office of Science, and Office of Biological and Environmental Research of the US Department of Energy under Contract no. DEAC02-05CH11231 as part of their Regional and Global Climate Modeling Program; and by the Next-Generation Ecosystem Experiments (NGEE Arctic) project, supported by the Office of Biological and Environmental Research in the DOE Office of Science under Contract No. DE-AC02-05CH11231.

Edited by: U. Seibt

\section{References}

Carslaw, H. S., and Jaeger, J. C.: Conduction of heat in solids, 2nd ed., Clarendon Press; Oxford University Press, Oxford Oxfordshire, New York, viii, 510 pp., 1986.

Crank, J., and Nicolson, P.: A Practical Method for Numerical Evaluation of Solutions of Partial Differential Equations of the HeatConduction Type, P. Camb. Philos. Soc., 43, 50-67, 1947.

Curry, C. L.: Modeling the soil consumption of atmospheric methane at the global scale, Global Biogeochem. Cy., 21, GB4012, doi:10.1029/2006gb002818, 2007.

Davidson, E. A., Savage, K. E., Trumbore, S. E., and Borken, W.: Vertical partitioning of $\mathrm{CO}_{2}$ production within a temperate forest soil, Glob. Change Biol., 12, 944-956, doi:10.1111/J.13652486.2005.01142.X, 2006.

Grant, R. F.: A review of the Canadian ecosystem model ecosys, in: Modeling Carbon and Nitrogen Dynamics for Soil Management, CRC Press, Boca, Raton, 173-264, ISBN 10:1566705290, 2001.

Maggi, F., Gu, C., Riley, W. J., Hornberger, G. M., Venterea, R. T., Xu, T., Spycher, N., Steefel, C., Miller, N. L., and Oldenburg, C. M.: A mechanistic treatment of the dominant soil nitrogen cycling processes: Model development, testing, and application, J. Geophys. Res.-Biogeo., 113, G02016, doi:10.1029/2007jg000578, 2008.

Moldrup, P., Olesen, T., Komatsu, T., Yoshikawa, S., Schjonning, P., and Rolston, D. E.: Modeling diffusion and reaction in soils: $\mathrm{X}$. A unifying model for solute and gas diffusivity in unsaturated soil, Soil Sci., 168, 321-337, doi:10.1097/00010694200305000-00002, 2003.

Oleson, K., Lawrence, D. M., Bonan, G. B., Drewniak, B., Huang, M., Koven, C. D., Levis, S., Li, F., Riley, W. J., Subin, Z. M., Swenson, S., Thornton, P. E., Bozbiyik, A., Fisher, R., Heald, C. L., Kluzek, E., Lamarque, J.-F., Lawrence, P. J., Leung, L. R., Lipscomb, W., Muszala, S. P., Ricciuto, D. M., Sacks, W. J., Sun, Y., Tang, J., and Yang, Z.-L.: Technical description of version 4.5 of the Community Land Model (CLM), NCAR Technical Note NCAR/TN-503+STR, 420 pp., doi:10.5065/D6RR1W7M, 2013.
Riley, W. J., Still, C. J., Torn, M. S., and Berry, J. A.: A mechanistic model of $\mathrm{H}_{2}{ }^{18} \mathrm{O}$ and $\mathrm{C}^{18} \mathrm{OO}$ fluxes between ecosystems and the atmosphere: Model description and sensitivity analyses, Global Biogeochem. Cy., 16, 1095, doi:10.1029/2002gb001878, 2002.

Riley, W. J., McKone, T. E., and Hubal, E. A. C.: Estimating contaminant dose for intermittent dermal contact: Model development, testing, and application, Risk Anal., 24, 73-85, doi:10.1111/J.0272-4332.2004.00413.X, 2004.

Riley, W. J., Subin, Z. M., Lawrence, D. M., Swenson, S. C., Torn, M. S., Meng, L., Mahowald, N. M., and Hess, P.: Barriers to predicting changes in global terrestrial methane fluxes: analyses using CLM4Me, a methane biogeochemistry model integrated in CESM, Biogeosciences, 8, 1925-1953, doi:10.5194/bg-8-19252011, 2011.

Simunek, J., and Suarez, D. L.: Modeling of Carbon-Dioxide Transport and Production in Soil .1. Model Development, Water Resour. Res., 29, 487-497, doi:10.1029/92wr02225, 1993.

Tang, J., Zhuang, Q., Shannon, R. D., and White, J. R.: Quantifying wetland methane emissions with process-based models of different complexities, Biogeosciences, 7, 3817-3837, doi:10.5194/bg-7-3817-2010, 2010.

Tang, J. Y. and Riley, W. J.: A new top boundary condition for modeling surface diffusive exchange of a generic volatile tracer: theoretical analysis and application to soil evaporation, Hydrol. Earth Syst. Sci., 17, 873-893, doi:10.5194/hess-17-873-2013, 2013.

Tang, J. Y., Riley, W. J., Koven, C. D., and Subin, Z. M.: CLM4BeTR, a generic biogeochemical transport and reaction module for CLM4: model development, evaluation, and application, Geosci. Model Dev., 6, 127-140, doi:10.5194/gmd-6-127-2013, 2013.

Tans, P. P.: Oxygen isotopic equilibrium between carbon dioxide and water in soils, Tellus B, 50, 163-178, doi:10.1034/J.16000889.1998.T01-1-00004.X, 1998.

Venterea, R. T. and Rolston, D. E.: Mechanistic modeling of nitrite accumulation and nitrogen oxide gas emissions during nitrification, J. Environ. Qual., 29, 1741-1751, doi:10.2134/jeq2000.00472425002900060003x, 2000.

Walter, B. P. and Heimann, M.: A process-based, climate-sensitive model to derive methane emissions from natural wetlands: Application to five wetland sites, sensitivity to model parameters, and climate, Global Biogeochem. Cy., 14, 745-765, doi:10.1029/1999gb001204, 2000.

Zhuang, Q., Melillo, J. M., Kicklighter, D. W., Prinn, R. G., McGuire, A. D., Steudler, P. A., Felzer, B. S., and Hu, S.: Methane fluxes between terrestrial ecosystems and the atmosphere at northern high latitudes during the past century: A retrospective analysis with a process-based biogeochemistry model, Global Biogeochem. Cy., 18, GB3010, doi:10.1029/2004gb002239, 2004.

Zhuang, Q. L., Chen, M., Xu, K., Tang, J. Y., Saikawa, E., Lu, Y. Y., Melillo, J. M., Prinn, R. G., and McGuire, A. D.: Response of global soil consumption of atmospheric methane to changes in atmospheric climate and nitrogen deposition, Global Biogeochem. Cy., 27, 650-663, doi:10.1002/Gbc.20057, 2013. 